\title{
A Comparative Energetic Analysis of Active and Passive Emission Control Systems Adopting Standard Emission Test Cycles
}

\author{
Angelo Algieri, Mario Amelio, and Pietropaolo Morrone \\ Mechanics Department, University of Calabria, Via P. Bucci-Cubo 46C, Arcavacata di Rende, 87030 Cosenza, Italy \\ Correspondence should be addressed to Angelo Algieri, a.algieri@unical.it
}

Received 30 April 2012; Accepted 22 October 2012

Academic Editor: Hing Kai Chan

Copyright (C) 2012 Angelo Algieri et al. This is an open access article distributed under the Creative Commons Attribution License, which permits unrestricted use, distribution, and reproduction in any medium, provided the original work is properly cited.

\begin{abstract}
The present work aims at analysing and comparing the thermal performances of active and passive aftertreatment systems. A one-dimensional transient model has been developed in order to evaluate the heat exchange between the solid and the exhaust gas and to estimate the energy effectiveness of the apparatus. Furthermore, the effect of the engine operating conditions on the performances of emission control systems has been investigated considering standard emission test cycles. The analysis has demonstrated that the active flow control presents the higher thermal inertia and it appears more suitable to maintain the converter initial temperature level for a longer time after variations in engine load. Conversely, the traditional passive flow control is preferable when rapid "cooling" or "heating" of the solid phase is requested. Moreover, the investigation has highlighted the significant influence of the cycle time and converter length on the energetic performances of the aftertreatment apparatus.
\end{abstract}

\section{Introduction}

The development and the optimisation of high efficiency aftertreatment systems are fundamental keys to meet the more and more severe regulations concerning automotive exhaust emissions $[1,2]$. A host of numerical and experimental investigations have been carried out in the last few decades to improve the energetic performances of emission control systems and reduce engine tailpipe emissions [3, 4]. Usually, the low temperatures of the exhaust gas in the lean burn engine impose the addition of supplemental fuel in order to guarantee the proper thermal level for standard aftertreatment systems. Consequently, a nonnegligible fuel penalty and a negative impact on engine efficiency are produced. In particular, high temperatures are required to initiate and sustain light-off condition for oxidation catalysts (OCs), to regenerate diesel particulate filters (DPFs), and to permit the desulfurization process for lean $\mathrm{NO}_{x}$ traps (LNTs) $[5,6]$. Moreover, a review of the literature reveals that all the emission control systems require proper operating temperatures and an accurate flow control to guarantee reliable and efficient processes. Nowadays, passive flow control represents the traditional technical solution largely adopted in automotive practice with unidirectional flow within the emission control system.

Conversely, in the last few years, an innovative active flow control has been proposed to assure the correct thermal level for energy efficient aftertreatment operations and to reduce the addition of supplemental fuel $[5,7]$. The new strategy is based on reversed flow systems and on the control of the exhaust flow through the aftertreatment device (Figure 1). Specifically, the exhaust gas is periodically switched between the two system ends by means of valves [8]. A cycle consists of forward and backward operations and it is defined as symmetric if the two consecutive processes last for the same time.

This work aims to compare the energy efficiency of aftertreatment systems with active and passive strategies. Several studies on emission control systems exist in the literature, while a few investigations refering to active flow control. The analysis is focused on the thermal behaviour of the system to compare different flow control strategies and to quantify the aftertreatment system response after sudden variations in engine load. The European Stationary emission 


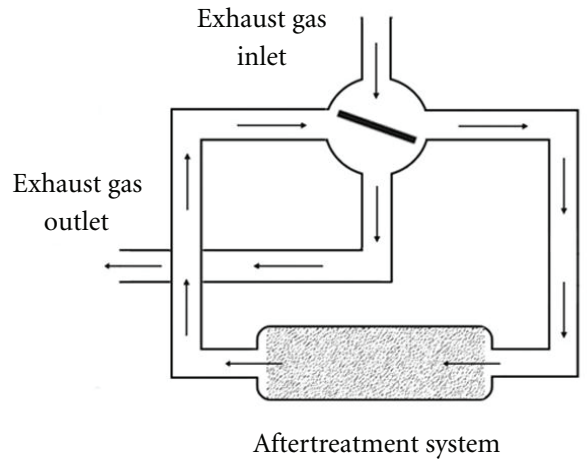

(a) Forward

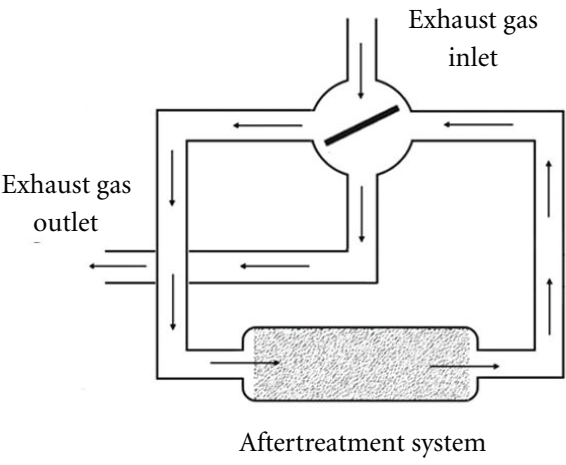

(b) Backward

FIgURE 1: Active aftertreatment system: forward (a) and backward (b) operations.

test Cycle (ESC) has been considered and the influence of the cycle time and the aftertreatment length on the energetic performances has been investigated.

\section{Numerical Model}

A one-dimensional single channel transient model was used to simulate the thermal exchange between the exhaust gas and the aftertreatment system. A structured monolith was analysed. The proposed numerical code simulates the thermal exchanges inside a single channel of the aftertreatment system. The basic model assumptions are the following: working fluid as ideal mixture, one-dimensional unsteady flow, and adiabatic systems towards the surroundings. The catalytic reactions are not taken into account and the results can be extended to a generic aftertreatment system with structured packed bed.

In accordance with the literature [9], the composition of the exhaust gas was calculated from the combustion of $\mathrm{C}_{12} \mathrm{H}_{24}$ with excess air. Referring to the control volume, the thermal exchange can be described as follows:

$$
\frac{\partial T}{\partial x}=\frac{h \cdot\left(P / A_{c}\right) \cdot\left(T_{s}-T\right)}{G \cdot c_{p}},
$$

where $h$ is the heat transfer coefficient; $x$ is the longitudinal coordinate; $P$ is the channel perimeter; $A_{c}$ is the cross area of a single channel; $T$ is the gas temperature; $T_{s}$ is the solid temperature; $G$ is the mass flow rate per unit area $A_{c} ; c_{p}$ is the specific heat of the working fluid.

The monolith temperature was calculated according to the following energy balance for the solid phase:

$$
\rho_{s} \cdot c \cdot S \cdot d x \cdot \frac{\partial T_{s}}{\partial t}=-G \cdot c_{p} \cdot d T,
$$

where $c$ is the specific heat of the solid phase; $\rho_{s}$ is the solid density; $t$ is the generic time.

The equations were solved with a finite difference scheme. More detail on the model and on the relative validation is reported in the literature $[10,11]$.

The heat transfer coefficient $h$ was obtained as a function of Reynolds (Re) and Prandtl (Pr) numbers, using the
TABle 1: Operative conditions for the working fluid and emission control systems.

\begin{tabular}{lc}
\hline $\begin{array}{l}\text { Reference converter size, } H W L \\
\text { (height; width; length) }\end{array}$ & $141 \mathrm{~mm}$ (41 mm $300 \mathrm{~mm}$ \\
Cell density, $c_{d}$ & $62 \mathrm{cell} / \mathrm{cm}^{2}$ \\
Channel size, $b$ & $0.90 \mathrm{~mm}$ \\
Wall thickness, $w$ & $0.35 \mathrm{~mm}$ \\
Wetted surface per unit volume, & $2201 \mathrm{~m}^{-1}$ \\
$S_{w} / V$ & $2807 \mathrm{~kg} / \mathrm{m}^{3}$ \\
Solid phase density, $\rho_{s}$ & $800 \mathrm{~J} / \mathrm{kg} \mathrm{K}$ \\
Solid specific heat capacity, $c$ & $100 \mathrm{~g} / \mathrm{s}$ \\
Exhaust flow rate, $\dot{m}$ & $200(700)^{\circ} \mathrm{C}$ \\
Exhaust gas temperature, $T_{\text {inlet }}$ & $700(200)^{\circ} \mathrm{C}$ \\
Initial solid temperature, $T_{s}$ & $20 \mathrm{~s}$ \\
Cycle time, $t$ & $22 \div 252 \mathrm{~g} / \mathrm{s}$ \\
\hline Further exhaust flow rate, $\dot{m}$ & $194 \div 616^{\circ} \mathrm{C}$ \\
Further exhaust gas temperature, & $194 \div 434^{\circ} \mathrm{C}$ \\
$T_{\text {inlet }}$ & $400 \div 600 \mathrm{~mm}$ \\
Further initial solid temperature, $T_{s}$ & $30 \div 60 \mathrm{~s}$ \\
Further converter length, $L$ & \\
Further cycle time, $t$ &
\end{tabular}

correlation attributed to Hausen [12] and adopted by Rafidi and Blasiak [13] to study the thermal exchange within a structured monolith:

$$
N u=h \cdot \frac{D_{\mathrm{eq}}}{k}=3.61+\frac{0.0668 \cdot\left(D_{\mathrm{eq}} / L\right) \operatorname{Re} \operatorname{Pr}}{1+0.04 \cdot\left[\left(D_{\mathrm{eq}} / L\right) \operatorname{Re} \operatorname{Pr}\right]^{2 / 3}} .
$$

\section{Operative Conditions}

The geometric characteristics and the operating conditions of the monolith aftertreatment system are shown in Table 1 for typical production heavy-duty diesel engines.

First, the aftertreatment "cooling" and "heating" processes were investigated. In particular, during the cooling phase, exhaust gas enters into the system at $200^{\circ} \mathrm{C}$, while 


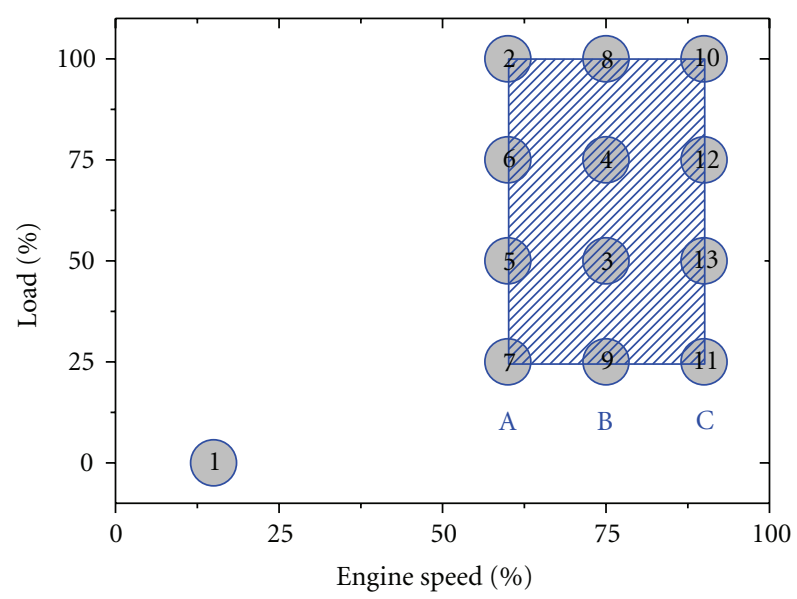

FIgure 2: European Stationary Cycle (ESC).

the initial solid temperature is $700^{\circ} \mathrm{C}$. This corresponds to a sudden decrease in the engine load after a long full load operation [5]. Conversely, during the heating process, the exhaust gas temperature is set at $700^{\circ} \mathrm{C}$, while the initial solid temperature is $200^{\circ} \mathrm{C}$.

Furthermore, to evaluate the influence of the engine operating conditions on the energetic performances of active and passive emission control systems, different engine conditions have been imposed. First of all, a progressive increase in the engine speed, followed by a progressive speed decrease has been considered.

Successively, the two control strategies have been compared over a sequence of steady-state modes according to the European Stationary Cycle (ESC) [14, 15], The test consists of 13 modes corresponding to different engine speeds and loads according to Figure 2. Specifically, the engine load percentage corresponds to $0,25,50,75$, and $100 \%$ while the engine speeds $A, B$, and $C$ are calculated as follows:

$$
\begin{aligned}
& A=n_{\mathrm{lo}}+0.25\left(n_{\mathrm{hi}}-n_{\mathrm{lo}}\right), \\
& B=n_{\mathrm{lo}}+0.50\left(n_{\mathrm{hi}}-n_{\mathrm{lo}}\right), \\
& C=n_{\mathrm{lo}}+0.75\left(n_{\mathrm{hi}}-n_{\mathrm{lo}}\right),
\end{aligned}
$$

where $n_{\mathrm{lo}}$ is the lowest engine speed that corresponds to $50 \%$ of the maximum net power; $n_{\mathrm{hi}}$ is the highest engine speed that corresponds to $70 \%$ of the maximum net power.

The characterisation of the thermal performances of the emission control system was achieved through the analysis of the temperature profile and the evaluation of the mean solid temperature $\left(T_{\text {mean }}\right)$ within the aftertreatment device:

$$
T_{\text {mean }}(t)=\frac{\int_{0}^{L} T(x, t) d x}{L} .
$$

Previous work showed that the temperature differences between gas and solid phase are negligible and tend to reduce with the operating time [16-19].

Finally, the influence of the cycle time and aftertreatment geometric characteristics has been investigated.

\section{Results}

The transient numerical model was used to predict the thermal and the energetic performances of emission control systems with active and passive flow control, respectively.

Figure 3(a) illustrates the evolution of solid temperature along the emission control system as a function of time. The figure refers to the passive flow control mode. Exhaust mass flow rate is $100 \mathrm{~g} / \mathrm{s}$. The initial temperature of the solid is imposed to $700^{\circ} \mathrm{C}$ while the exhaust gas temperature is $200^{\circ} \mathrm{C}$. This operating condition simulates the exhaust gas at low load engine operation after a long period of high load [5].

The investigation highlights the great influence of operating time on the temperature distribution within the monolith. The leading part of the emission control system is almost completely cooled after 30 seconds, while at the outlet, the temperature values are close to $700^{\circ} \mathrm{C}$. Furthermore, the solid appears completely cooled after 100 seconds.

The evolution of temperature profiles with the active flow control for the previous operating conditions is shown in Figure 3(b). The cycle time is 20 seconds. The analysis revealed that the reverse flow operation determines a different temperature distribution within the aftertreatment apparatus. A maximum temperature value is located at the central region of the system, with a progressive decrease from about $650^{\circ} \mathrm{C}$ at 30 seconds to $460^{\circ} \mathrm{C}$ at 100 seconds.

The comparison with the results obtained with conventional unidirectional flow highlights the greater thermal retention capacity of the active emission control system. Specifically, for the passive control system, the solid phase is almost completely cooled after $100 \mathrm{~s}$. Conversely, the active control maintains significantly higher temperature values in the monolith central area. An increase of about $260^{\circ} \mathrm{C}$ is found. When high temperatures are required, the reverse flow control determines the maintenance of suitable temperatures for the proper operation of the system, even under lean mixture conditions and low load operation, without additional fuel. Therefore, the active technique permits a significant energy savings with respect to the passive control strategy. 


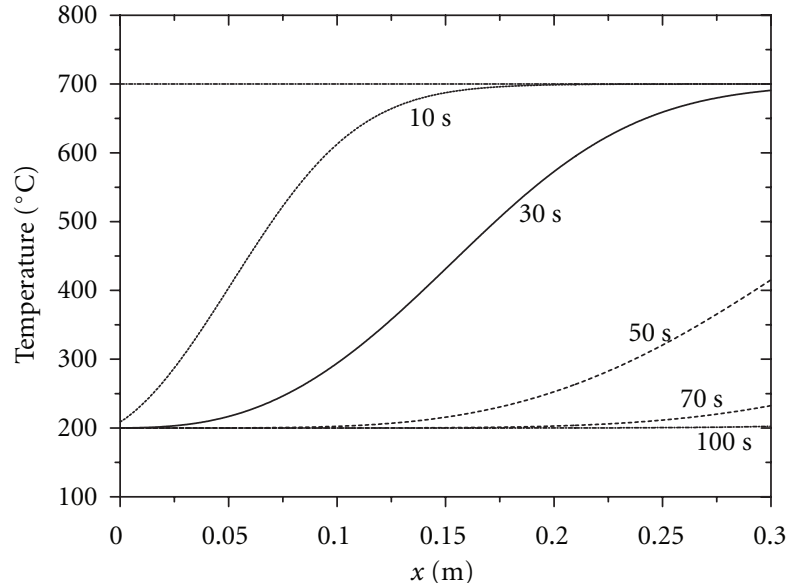

(a)

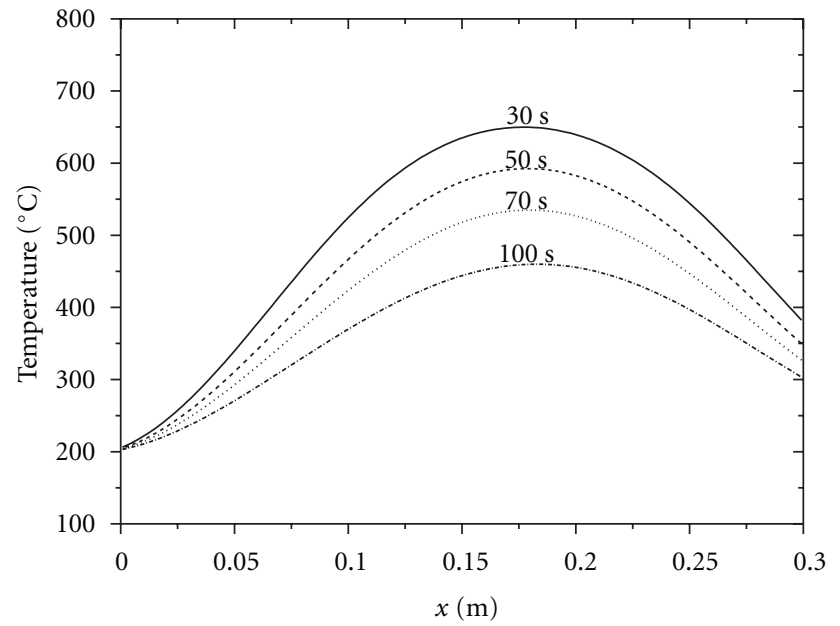

(b)

FIgURE 3: Temperature profiles along the aftertreatment system as a function of time. Cooling phase. Passive (a) and active (b) flow control operations.

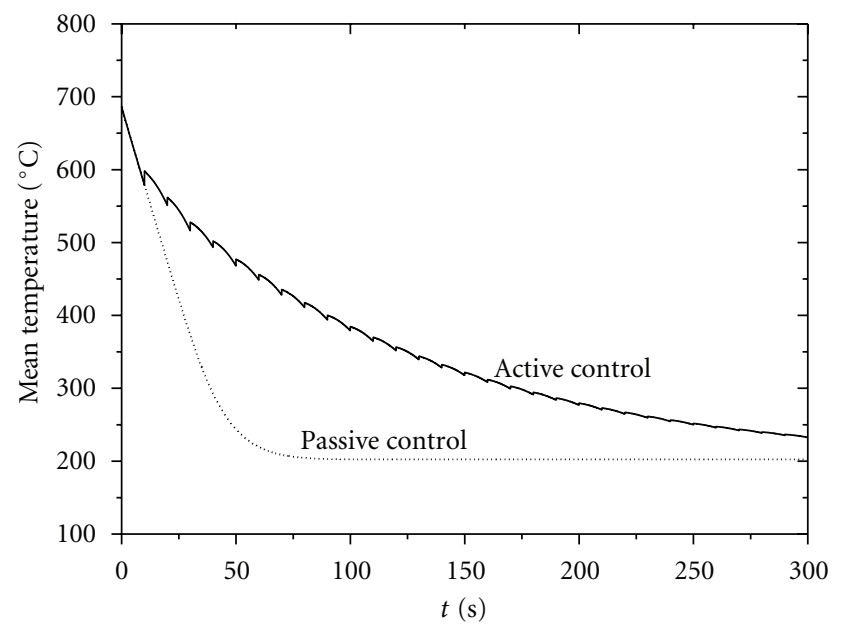

Figure 4: Mean temperature profiles as a function of operating time.

Figure 4 shows the mean temperature comparison for the two operating modes within the emission control system. The results confirm that the temperature of the system without reverse flow falls to the exhaust gas temperature $\left(200^{\circ} \mathrm{C}\right)$ after 100 seconds. A value of nearly 47\% higher is found when the active control is used and the thermal level of the system reaches $230^{\circ} \mathrm{C}$ after 300 seconds, a temperature value which is $13 \%$ higher than the corresponding value of the passive flow control. These differences are due to the better thermal retention characteristics of the reverse operation.

The comparison between active and passive operation was repeated considering the solid heating process in order to analyse the effect of the reversal flow control in more detail (Figure 5). In particular, the solid initial temperature is $200^{\circ} \mathrm{C}$, the temperature of exhaust gas is $700^{\circ} \mathrm{C}$, and the exhaust mass flow rate is $100 \mathrm{~g} / \mathrm{s}$. This condition corresponds to high load engine operation after a long period of low load operation. When passive control is adopted (Figure 5(a)), the converter leading region is almost completely heated after 30 seconds, while the opposite end retains temperature values close to $200^{\circ} \mathrm{C}$. However, the aftertreatment system appears totally heated (close to $700^{\circ} \mathrm{C}$ ) after 70 seconds.

The temperature profiles with the active flow control during the heating process are shown in Figure 5(b). The comparison with the previous results highlights a greater thermal inertia of the active control system and, as a consequence, a greater delay in reaching a high thermal level. Specifically, after $100 \mathrm{~s}$ the temperature in the central part of the aftertreatment system is lower than $440^{\circ} \mathrm{C}$. The mean temperature profiles within the aftertreatment system confirms the results already discussed.

To evaluate the influence of the engine operating conditions on the energetic performances of active and passive emission control systems, a progressive increase in the engine speed, followed by a progressive speed decrease, has been considered. Each engine regime has been maintained for $120 \mathrm{~s}$ 


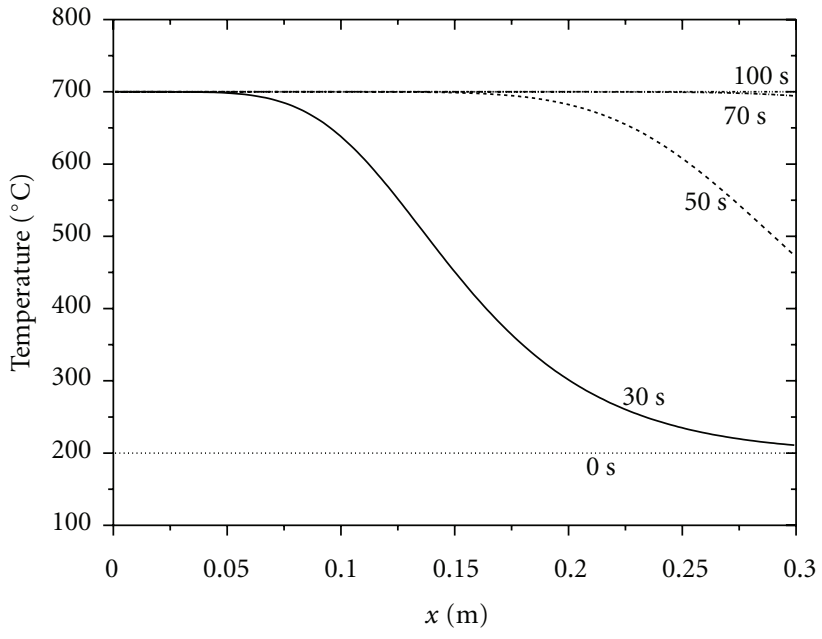

(a)

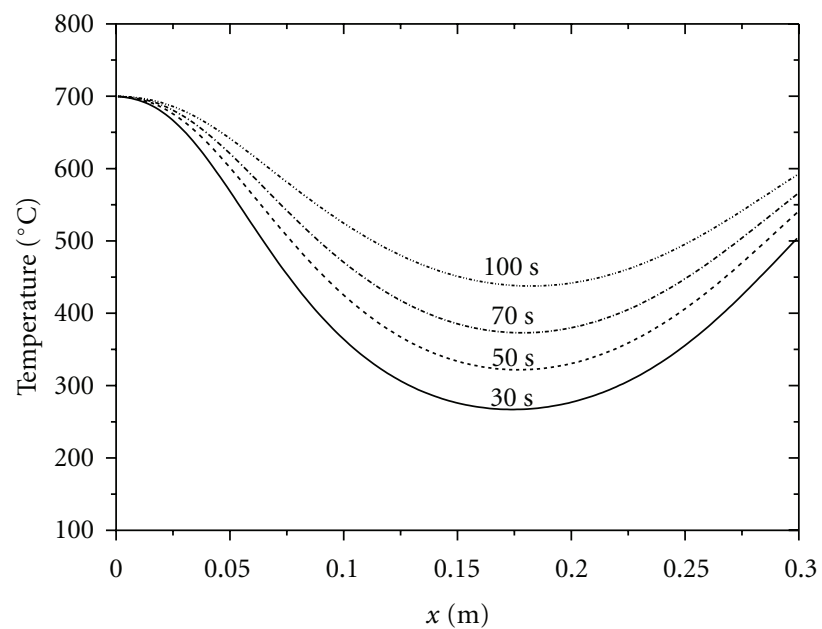

(b)

Figure 5: Temperature profiles along the aftertreatment system as a function of time. Heating phase. Passive (a) and active (b) flow control operations.

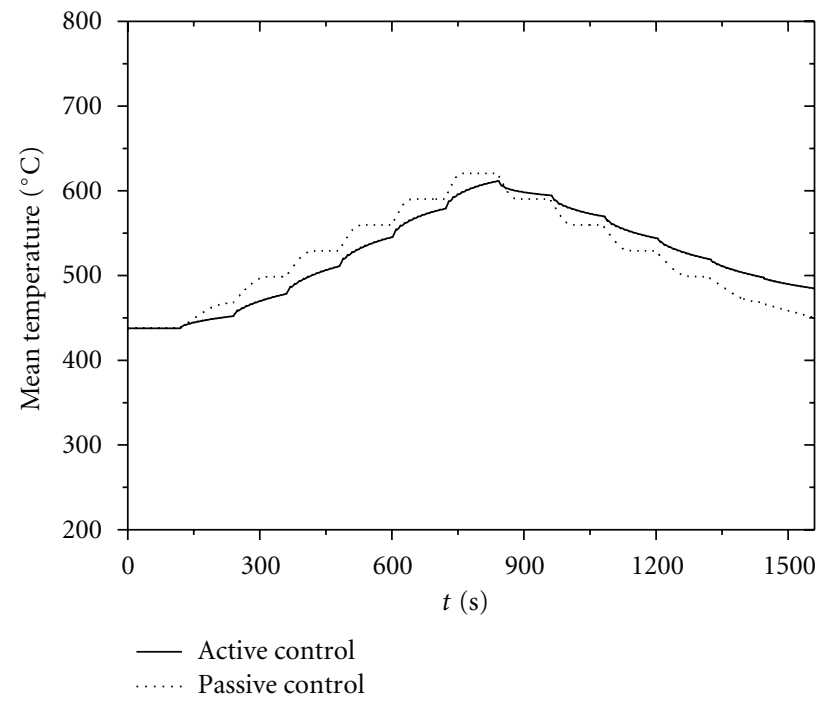

Figure 6: Mean temperature profiles as a function of operating time. First steady-state test cycle.

as visible on Table 2 that summarises the exhaust mass flow rates and the corresponding exhaust temperatures as a function of engine speed. Data refer to a multi-cylinder diesel engine with turbocharger, whose performances have been estimated using a commercial code (AVL Boost).

Mean temperature profiles within the emission control system are plotted in Figure 6. The unidirectional flow operation is characterised by a lower thermal inertia and the device mean temperature profile reproduces the input step engine load variation more accurately. Specifically, when the engine speed increases, the mean thermal level of the passive system is higher than the active one. Conversely, the mean temperature of passive system decreases faster as the engine speed reduces.

Finally, the two control strategies have been compared over a sequence of 13 steady-state modes according to the
European Stationary Cycle (ESC). Table 3 summarises the operating conditions [20].

Figure 7 depicts that at the beginning of the simulation the solid and exhaust gas present the same temperature $\left(194^{\circ} \mathrm{C}\right)$. As a consequence, during the first 4 minutes the thermal exchange is absent. For the heating processes (even modes) the solid is heated by the incoming gas and, as already discussed, the passive control reaches higher mean temperature. The largest temperature difference between passive and active control is found during the second mode (about $\left.150^{\circ} \mathrm{C}\right)$.

When the load decreases (odd modes) the temperature of the passive system reduces rapidly, while the thermal inertia of the active system maintains higher temperatures.

In order to investigate in more detail the influence of the flow control strategy on the aftertreatment thermal 


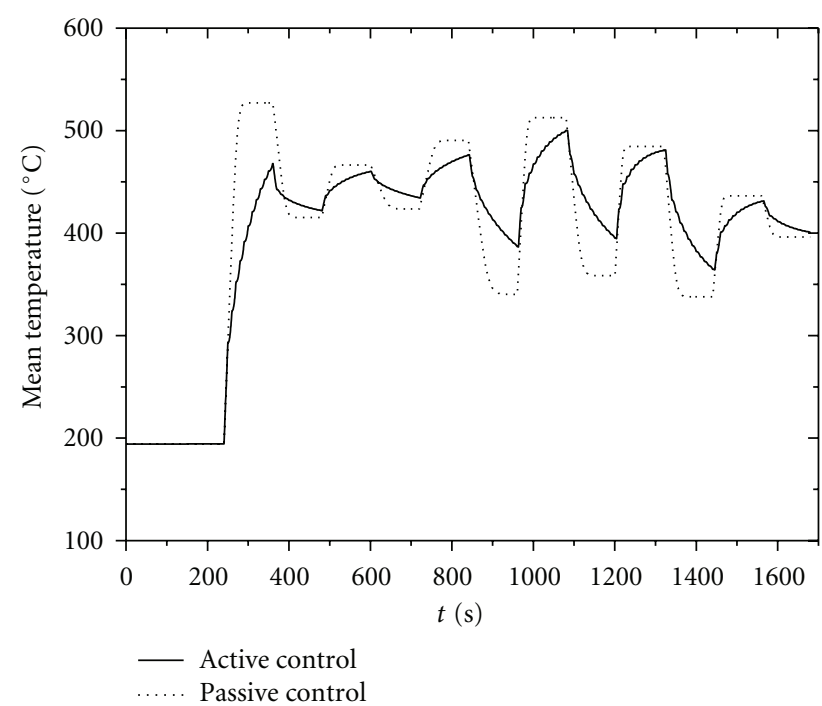

FIGURE 7: Mean temperature profiles as a function of operating time. European Stationary Cycle (ESC).

TABLe 2: First steady-state test cycle.

\begin{tabular}{lcccc}
\hline Mode & $\begin{array}{c}\text { Engine speed } \\
(\mathrm{rpm})\end{array}$ & $\begin{array}{c}\text { Time } \\
(\mathrm{min})\end{array}$ & $\begin{array}{c}\text { Exhaust } \\
\text { temperature }\left({ }^{\circ} \mathrm{C}\right)\end{array}$ & $\begin{array}{c}\text { Mass flow } \\
\text { rate }(\mathrm{kg} / \mathrm{s})\end{array}$ \\
\hline 1 & 1000 & 2 & 434 & 0.022 \\
2 & 1500 & 2 & 464 & 0.055 \\
3 & 2000 & 2 & 495 & 0.083 \\
4 & 2500 & 2 & 525 & 0.106 \\
5 & 3000 & 2 & 556 & 0.127 \\
6 & 3500 & 2 & 586 & 0.143 \\
7 & 4000 & 2 & 616 & 0.157 \\
8 & 3500 & 2 & 586 & 0.143 \\
9 & 3000 & 2 & 556 & 0.127 \\
10 & 2500 & 2 & 525 & 0.106 \\
11 & 2000 & 2 & 495 & 0.083 \\
12 & 1500 & 2 & 464 & 0.055 \\
13 & 1000 & 2 & 434 & 0.022 \\
\hline
\end{tabular}

behaviour, the effect of the cycle time has been analysed (Figure 8). The mean temperature curves, related to the active control aftertreatment systems, are catenary. During the second mode, before the first inversion, the system with active control behaves as a passive aftertreatment apparatus and the active and passive profiles overlap. Furthermore, the higher the cycle times, the lower the thermal inertia, and, as a consequence, the mean solid temperature tends to the passive behaviour.

Finally, the large effect of the device length on the mean thermal level is shown in Figure 9.

The plot refers to four monolith lengths (from 300 to $600 \mathrm{~mm}$ ): the higher the monolith lengths, the higher the thermal inertias. The passive flow control presents slight differences in the mean temperature profiles. Conversely, for
TABLE 3: European Stationary Cycle (ESC) test.

\begin{tabular}{lcccc}
\hline Mode & $\begin{array}{c}\text { Engine speed } \\
(\mathrm{rpm})\end{array}$ & $\begin{array}{c}\text { Time } \\
(\mathrm{min})\end{array}$ & $\begin{array}{c}\text { Exhaust } \\
\text { temperature }\left({ }^{\circ} \mathrm{C}\right)\end{array}$ & $\begin{array}{c}\text { Mass flow } \\
\text { rate }(\mathrm{kg} / \mathrm{s})\end{array}$ \\
\hline 1 & 700 & 4 & 194 & 0.054 \\
2 & 1212 & 2 & 527 & 0.151 \\
3 & 1525 & 2 & 415 & 0.147 \\
4 & 1525 & 2 & 466 & 0.173 \\
5 & 1212 & 2 & 423 & 0.110 \\
6 & 1212 & 2 & 490 & 0.127 \\
7 & 1212 & 2 & 340 & 0.098 \\
8 & 1525 & 2 & 513 & 0.197 \\
9 & 1525 & 2 & 358 & 0.125 \\
10 & 1837 & 2 & 484 & 0.252 \\
11 & 1837 & 2 & 338 & 0.154 \\
12 & 1837 & 2 & 436 & 0.217 \\
13 & 1837 & 2 & 396 & 0.181 \\
\hline
\end{tabular}

the active configuration, the results highlight that the differences reduce with the operating time. As an example, by increasing the aftertreatment length from 300 to $600 \mathrm{~mm}$, the mean temperature difference reaches $122^{\circ} \mathrm{C}$ and $37^{\circ} \mathrm{C}$ at 360 and $1440 \mathrm{~s}$, respectively.

The analysis demonstrates that, if high temperatures are required for the proper functioning of the aftertreatment system, the active control is useful at low load operating condition with the solid at high temperature. Conversely, the passive control system is recommended during the warm-up phase and/or to accelerate the cooling or the heating process.

Depending on the engine load and the requested converter thermal level, the coupled operation of active and passive flow represents the solution apt to guarantee the highest energy efficiencies. 


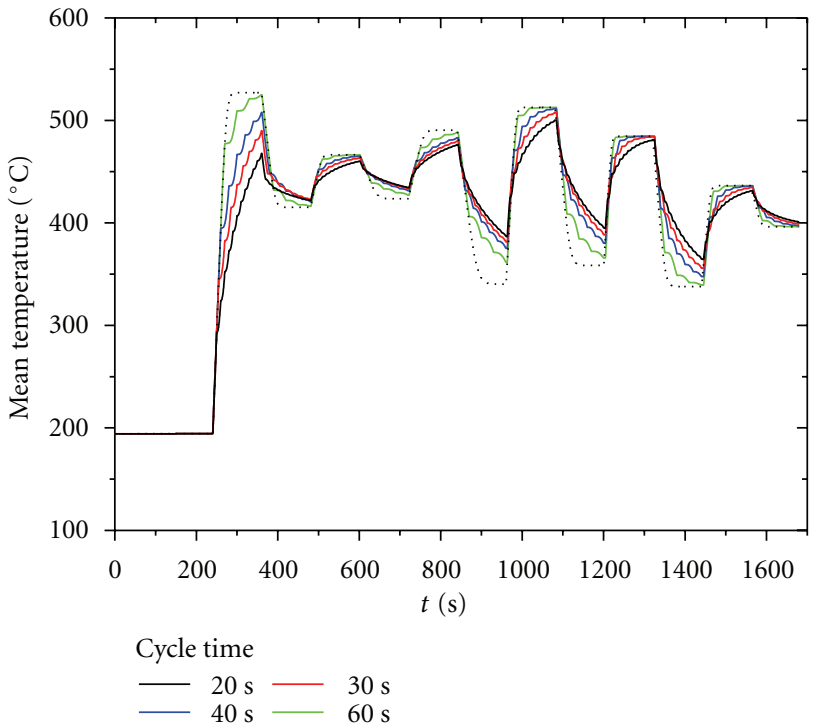

Figure 8: Influence of the cycle time on the mean temperature profiles. Solid line: active control; dotted line: passive control. European Stationary Cycle (ESC).

\section{Conclusions}

A one-dimensional transient model has been developed in order to analyse and compare the energetic performances of passive and active emission control systems. Specifically, the numerical model enables the calculation of the heat exchange and the temperature profiles of solid and exhaust gas.

The effect of the engine load on the system behaviour has been analysed and the influence of the cycle time and monolith length on the energy efficiency of the system has been investigated. To this purpose, two sequences of steadystate modes have been imposed. The first operation is based on a progressive increase in the engine speed, followed by a progressive engine speed decrease. The European Stationary Cycle (ESC) for heavy-duty diesel engines has been also considered.

The comparison between active and passive flow control showed the greatest thermal inertia of reverse operation. When the load increases, the temperature of the active system upsurges slightly, while the low thermal inertia of the passive system determines higher temperatures. Conversely, a decrease in the engine load produces higher temperatures for the reversed flow configuration.

The active control appears more suitable to maintain the solid initial temperature level for a longer time after sudden variations in engine load, even under lean mixture conditions and low load operation. The traditional unidirectional operation is preferable when rapid cooling or heating of the aftertreatment system is demanded.

Furthermore, the numerical investigation demonstrated that the energy performances of the active control approach those of the passive control system as the cycle time increases.

Finally, the significant effect of the converter length on the thermal system behaviour has been analysed: the higher the monolith lengths, the higher the thermal inertias. In

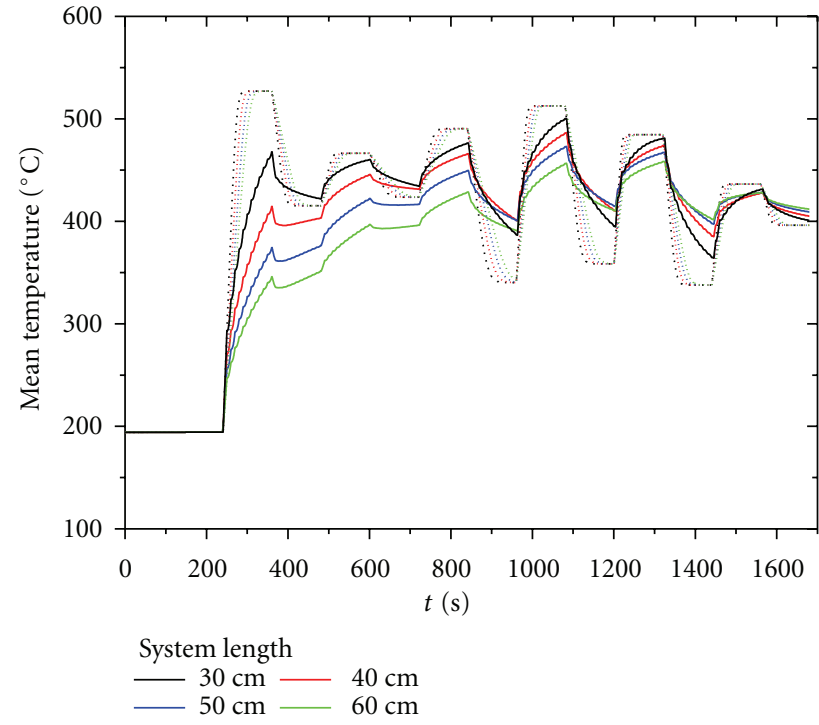

FIGURE 9: Influence of the converter length on the mean temperature profiles. Solid line: active control; dotted line: passive control. European Stationary Cycle (ESC).

particular, for the active flow control the differences in temperature profiles as a function of the device length reduce with the operating time.

\section{Acknowledgment}

The authors would like to thank AVL List GmbH for the provision of the AVL Boost software.

\section{References}

[1] T. J. Wang, S. W. Baek, and J. H. Lee, "Kinetic parameter estimation of a diesel oxidation catalyst under actual vehicle operating conditions," Industrial and Engineering Chemistry Research, vol. 47, no. 8, pp. 2528-2537, 2008.

[2] T. V. Johnson, "Diesel emission control in review," SAE International Journal of Fuels and Lubricants, vol. 115, SAE paper 2006-01-0030, no. 1, pp. 1-15, 2009.

[3] J. B. Heywood, Internal Combustion Engine Fundamentals, Mc Graw Hill, New York, NY, USA, 1998.

[4] A. Algieri, "Experimental investigation of the fluid dynamic efficiency of a high performance multi-valve internal combustion engine during the intake phase. Influence of valve-valve interference phenomena," Thermal Science. In press.

[5] M. Zheng and G. T. Reader, "Energy efficiency analyses of active flow aftertreatment systems for lean burn internal combustion engines," Energy Conversion and Management, vol. 45, no. 15-16, pp. 2473-2493, 2004.

[6] E. Cauda, D. Fino, G. Saracco, and V. Specchia, "Preparation and regeneration of a catalytic diesel particulate filter," Chemical Engineering Science, vol. 62, no. 18-20, pp. 51825185, 2007.

[7] B. Liu, R. E. Hayes, M. D. Checkel, and M. Zheng, "Reversing flow catalytic converter for a natural gas/diesel dual fuel engine," Chemical Engineering Science, vol. 56, no. 8, pp. 2641$2658,2001$. 
[8] Y. S. Matros, G. A. Bunimovich, V. O. Strots, and E. A. Mirosh, "Reversed flow converter for emission control after automotive engines," Chemical Engineering Science, vol. 54, no. 13-14, pp. 2889-2898, 1999.

[9] P. Singh, A. M. Thalagavara, J. D. Naber et al., "An experimental study of active regeneration of an advanced catalyzed particulate filter by diesel fuel injection upstream of an oxidation catalyst," SAE International Journal of Fuels and Lubricants, vol. 115, SAE paper 2006-01-0879, pp. 334-357, 2006.

[10] M. Amelio and P. Morrone, "Numerical evaluation of the energetic performances of structured and random packed beds in regenerative thermal oxidizers," Applied Thermal Engineering, vol. 27, no. 4, pp. 762-770, 2007.

[11] M. Amelio, G. Florio, P. Morrone, and S. Senàtore, "The influence of rotary valve distribution systems on the energetic efficiency of regenerative thermal oxidizers (RTO)," International Journal of Energy Research, vol. 32, no. 1, pp. 24-34, 2008.

[12] F. Incropera and D. De Witt, Fundamentals of Heat and Mass Transfer, Wiley \& Sons, New York, NY, USA, 2002.

[13] N. Rafidi and W. Blasiak, "Thermal performance analysis on a two composite material honeycomb heat regenerators used for HiTAC burners," Applied Thermal Engineering, vol. 25, no. 17-18, pp. 2966-2982, 2005.

[14] J. Krahl, G. Knothe, A. Munack et al., "Comparison of exhaust emissions and their mutagenicity from the combustion of biodiesel, vegetable oil, gas-to-liquid and petrodiesel fuels," Fuel, vol. 88, no. 6, pp. 1064-1069, 2009.

[15] H. Kim and B. Choi, "The effect of biodiesel and bioethanol blended diesel fuel on nanoparticles and exhaust emissions from CRDI diesel engine," Renewable Energy, vol. 35, no. 1, pp. 157-163, 2010.

[16] A. Algieri, M. Amelio, and P. Morrone, "Energetic analysis of the performances of innovative aftertreatment systems," in Proceedings of the SAE Fuels and Lubricants Meeting, SAE paper 2009-01-1948, Florence, Italy, 2009.

[17] P. Morrone and A. Algieri, "Numerical investigation on the energetic performances of conventional and pellet aftertreatment systems in flow-through and reverse-flow designs," Thermal Science, vol. 15, pp. 1049-1064, 2011.

[18] A. Algieri, M. Amelio, S. Bova, and P. Morrone, "Energy efficiency analysis of monolith and pellet emission control systems in unidirectional and reverse-flow designs," SAE International Journal of Engines, vol. 2, no. 2, pp. 684-693, 2010.

[19] A. Algieri, M. Amelio, and P. Morrone, "A numerical analysis of energetic performances of active and passive after treatment systems," International Journal of Energy Research, vol. 33, no. 7, pp. 696-708, 2009.

[20] I. Iaccio, Sistemi di post trattamento dei gas di scarico di motori diesel [Ph.D. thesis], 2006. 

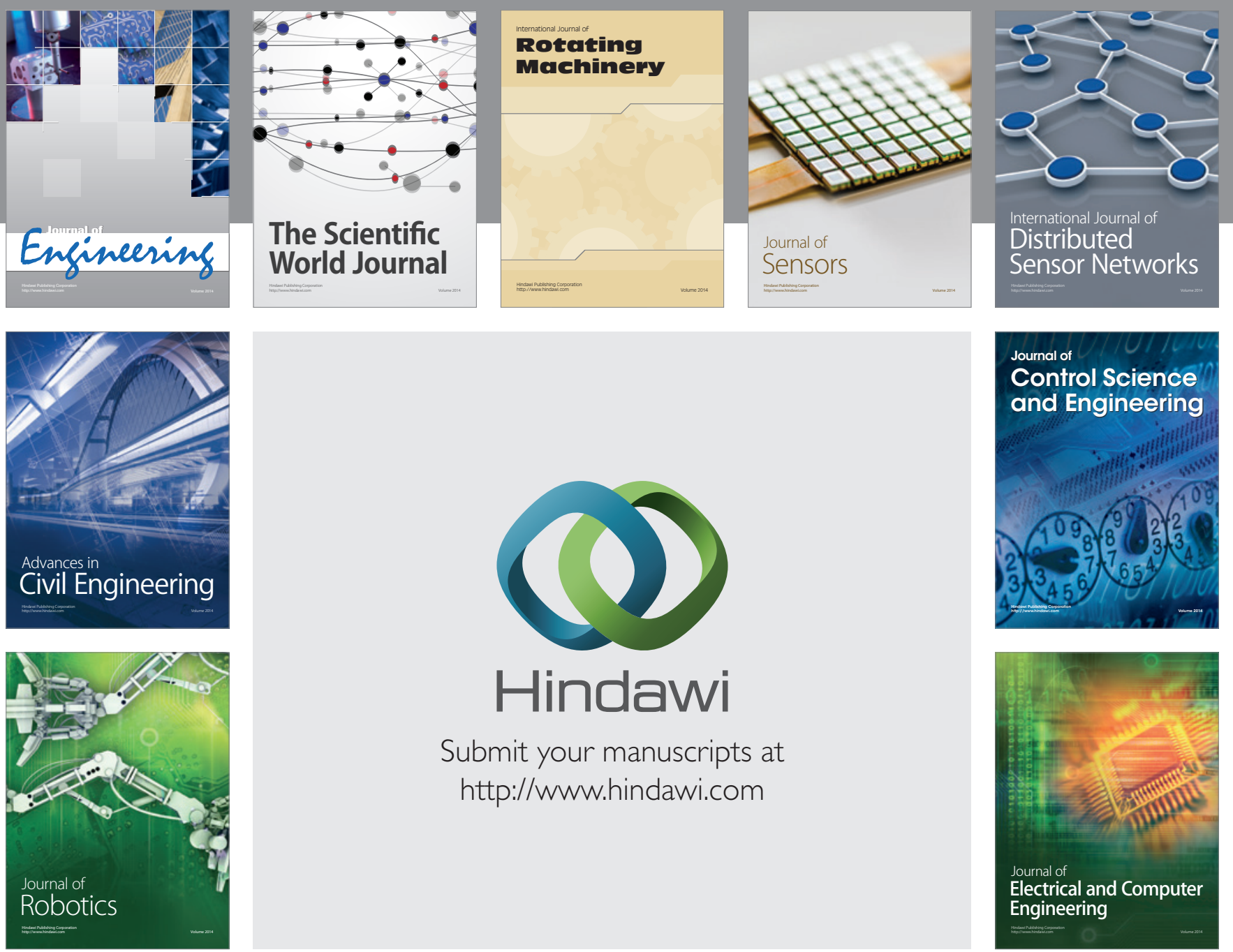

Submit your manuscripts at

http://www.hindawi.com
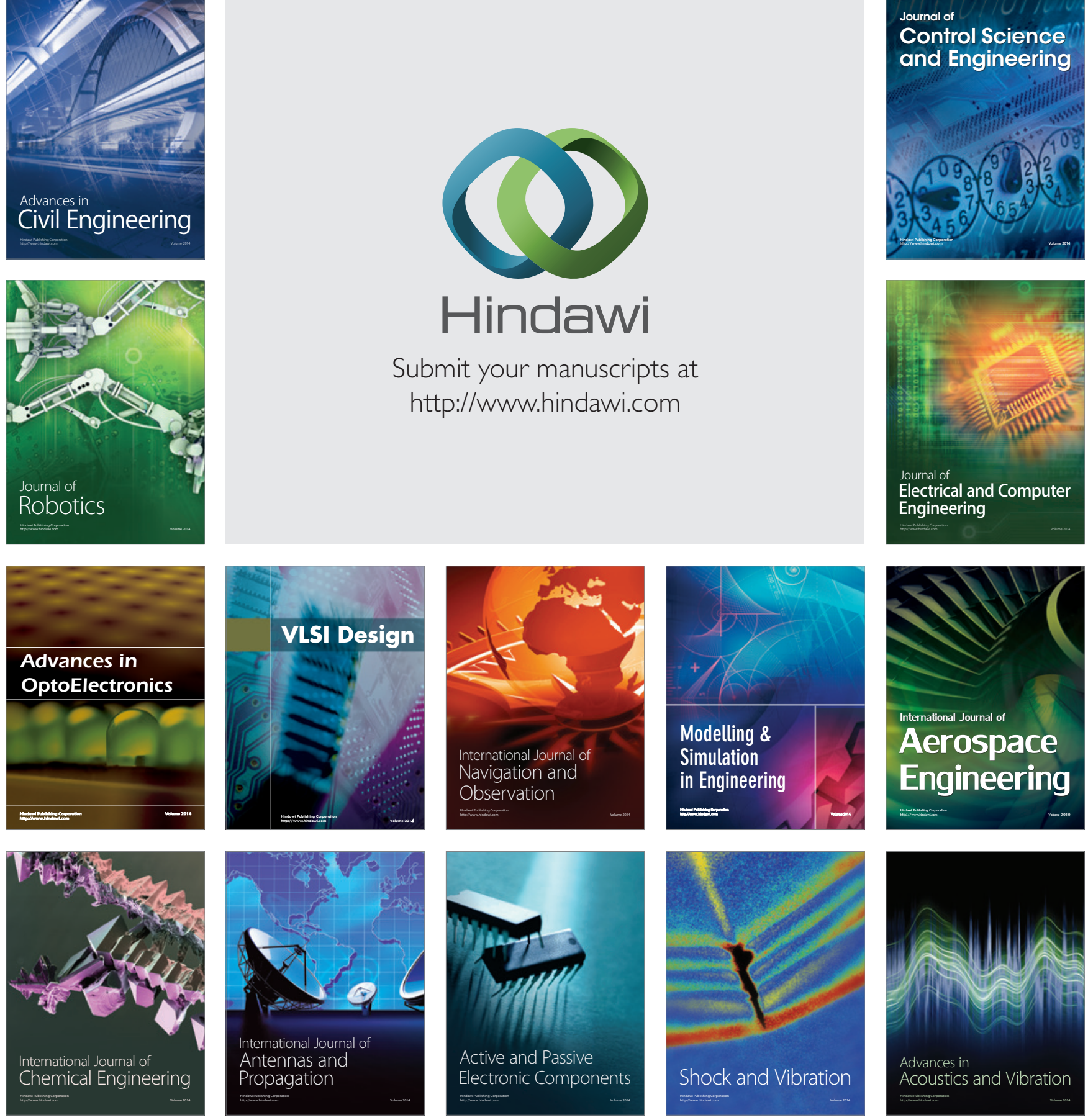